\title{
Study on hydrodynamic response characteristics of floating platform and supporting ship near island reef
}

\author{
Zhidong Wang, Yaqiu Liu
}

\begin{abstract}
Based on the potential flow theory, the Laplace equation and the Green's function are used to establish a three-dimensional numerical flow field, and the hydrodynamic characteristics of the platform are numerically simulated. Different wind and wave parameters are selected to discuss the six-degree-of-freedom RAO of the platform. Order wave forces and additional mass. By comparing the relevant parameters of the two numerical simulations, the influence of the ship's support on the hydrodynamic parameters of the platform is obtained.
\end{abstract}

Index Terms - Potential flow theory, hydrodynamics, wind and waves, Ship docked

\section{INTRODUCTION}

Near the island reef reef stretched hundreds of meters, because the water depth is very shallow, the cargo ship can not be berthed, large mechanical equipment is difficult to run on the island. Whether the platform is in working condition, towed state or storm self-storage state, the platform is affected by various environmental loads. ${ }^{[1]}$ 。 Because the interaction between the ship and the floating platform will cause complex changes in the motion response of the floating platform, it is particularly important to study the floating platform and the ship's assisted coupling movement.

For the hydrodynamic analysis theory of offshore platforms, the three-dimensional potential flow theory ${ }^{[2-3]}$ and Morison theory are the two most common theories. In order to analyze the hydrodynamic performance of offshore platforms, a large number of studies have been carried out at home and abroad. Zhang Wei ${ }^{[4]}$ took the $1500 \mathrm{~m}$ semi-submersible platform as the research object, carried out the numerical calculation in the frequency domain, obtained the motion response result of the platform, and compared the numerical results with the model test results. Xiao Yuwei ${ }^{[5]}$ used software AQWA to obtain the six-degree-of-freedom response amplitude operator of three types of tension leg platforms under regular waves, and analyzed the characteristics of hydrodynamic performance. Mansour ${ }^{[6]}$ carried out numerical calculations on the new semi-submersible platform and compared it with the RAO values of the prototype semi-submersible platform. Clauss ${ }^{[7]}$ used the GVA4000 semi-submersible platform as the research object, carried out numerical calculations, and compared the numerical results of the induced waves with the experimental results, and found that the degree of coincidence was higher.

Zhidong Wang, Professor, doctoral tutor, Mainly Engaged in Research Work on Fluid Dynamic Performance of Marine and Offshore Engineering, China.

Yaqiu Liu, Postgraduate of Naval Architecture and Ocean Engineering department of Jiangsu University of Science and Technology, China $+861885140629$
Lowa ${ }^{[8]}$ studied and analyzed the first-order and second-order motions of floating platforms in the time domain and frequency domain.

Based on the potential flow theory software AQWA, the numerical calculation and post-processing analysis of the hydrodynamic performance and motion response of the floating platform in the ship's support are carried out. The frequency domain calculation and analysis of the hydrodynamics of the ship's floating platform is completed.

\section{THREE-DIMENSIONAL POTENTIAL FLOW THEORY}

The conditions of the potential flow theory mainly include the following: the fluid is an ideal fluid, and has no viscosity, uniform distribution, incompressibility, and no rotation; there is a velocity potential in the flow field.For the potential flow, the velocity potential function is introduced, and the velocity potential function satisfies the Laplace equation, ie

$$
\frac{\partial^{2} \phi}{\partial x^{2}}+\frac{\partial^{2} \phi}{\partial y^{2}}+\frac{\partial^{2} \phi}{\partial z^{2}}=0
$$

According to the definition of the velocity potential function, the velocity of the fluid in three directions can be obtained, as shown in equation (2.2):

$$
v_{x}=\frac{\partial \phi}{\partial x}, v_{y}=\frac{\partial \phi}{\partial y}, v_{z}=\frac{\partial \phi}{\partial z}
$$

If the boundary conditions and initial conditions are known, the Laplace equation can solve the velocity potential function.

\section{FLOATING PLATFORM CALCULATION MODEL ESTABLISHMENT}

\section{A. Floating platform and supporting ship parameters}

The floating platform used in this chapter is $100 \mathrm{~m}$ in length, $25 \mathrm{~m}$ in full width and $2.7 \mathrm{~m}$ in draft. The total length of the ship is $95 \mathrm{~m}$, the full width is $20 \mathrm{~m}$, and the draft is $2.4 \mathrm{~m}$. The parameters of the floating platform and the hydrostatic parameters are shown in Table 1. Table 2, ship size parameters are shown in Table 3

Tab.1 Main parameters of floating platform

parameter name $\begin{gathered}\text { Numerical } \\ \text { value }\end{gathered}$

$\begin{array}{ccc}\text { length } & 100.00 & \mathrm{~m} \\ \text { width } & 25.00 & \mathrm{~m} \\ \text { Deepth } & 6.00 & \mathrm{~m}\end{array}$


$\underline{\text { Tab.2 Hydrostatic force parameters of floating platform }}$

\begin{tabular}{|c|c|c|}
\hline parameter name & Unit & Job status \\
\hline Draught & $\mathrm{m}$ & 2.7 \\
\hline Displacement & $\mathrm{t}$ & 6498 \\
\hline $\begin{array}{c}\text { Center of gravity } \\
\text { on the } \mathrm{X} \text { axis }\end{array}$ & $\mathrm{m}$ & 0.00 \\
\hline $\begin{array}{l}\text { Center of gravity } \\
\text { on the } \mathrm{Y} \text { axis }\end{array}$ & $\mathrm{m}$ & 0.00 \\
\hline $\begin{array}{c}\text { Center of gravity } \\
\text { height on the } Z \\
\text { axis }\end{array}$ & $\mathrm{m}$ & 1.60 \\
\hline $\begin{array}{l}\text { Moment of inertia } \\
\text { Ixx for the } X \text { axis }\end{array}$ & $\mathrm{kg} \cdot \mathrm{m}^{2}$ & $3.98 \mathrm{E}+08$ \\
\hline $\begin{array}{l}\text { Moment of inertia } \\
\text { to the Y axis Iyy }\end{array}$ & $\mathrm{kg} \cdot \mathrm{m}^{2}$ & $5.58 \mathrm{E}+09$ \\
\hline $\begin{array}{l}\text { Moment of inertia } \\
\text { to the } \mathrm{Z} \text { axis Izz }\end{array}$ & $\mathrm{kg} \cdot \mathrm{m} 2$ & $5.68 \mathrm{E}+09$ \\
\hline
\end{tabular}

Tab.3 Main parameters of ship

\begin{tabular}{ccc}
\hline parameter name & Numerical value & unit \\
\hline length & 95.00 & $\mathrm{~m}$ \\
width & 20.00 & $\mathrm{~m}$ \\
Deepth & 5.00 & $\mathrm{~m}$ \\
\hline
\end{tabular}

\section{B. Floating platform and supporting ship geometry model}

In order to facilitate the convenience of numerical simulation calculation, the body coordinate system is defined as: the origin point waterline surface, the $X$ axis is at the center line, the head of the floating platform is positive; the $\mathrm{Y}$ axis is pointing to the port side is positive; the $\mathrm{Z}$ axis is perpendicular to the The waterline is upright. As shown in Figure 1-2, it is the main and top view of the floating platform.

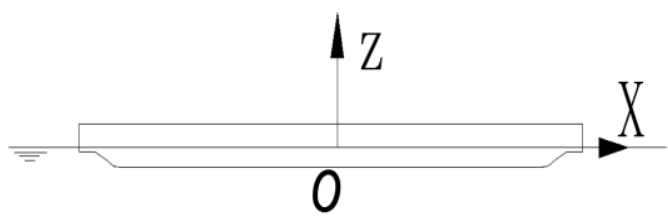

Fig.1 Main view of floating platform

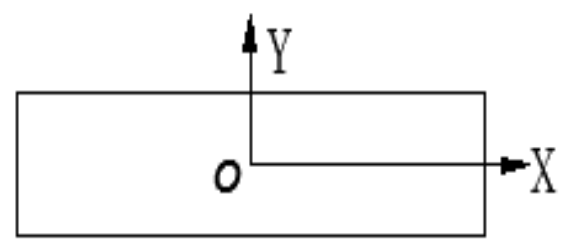

Fig.2 Top view of floating platform

\section{Calculation case setting}

In order to study the safety of the mooring system when the floating platform is supported by the ship, under the effect of the wind and wave, a total of 15 calculation conditions are set according to the difference between the sense wave height and the wave angle.
Tab.4 Calculation condition table

\begin{tabular}{|c|c|c|c|c|c|c|c|}
\hline $\begin{array}{l}\text { Workin } \\
\text { g } \\
\text { conditi } \\
\text { on }\end{array}$ & $\begin{array}{l}\text { Righteou } \\
\text { s wave } \\
\text { height } \\
H s(\mathrm{~m})\end{array}$ & $\begin{array}{l}\text { Peak } \\
\text { period } \\
T p(\mathrm{~s})\end{array}$ & $\begin{array}{c}\text { Wave } \\
\text { angle } \\
\beta_{1} \\
\left({ }^{\circ}\right)\end{array}$ & $\begin{array}{l}\text { Wind } \\
\text { speed } \\
V_{w}( \\
\mathrm{m} / \mathrm{s})\end{array}$ & $\begin{array}{c}\text { wind } \\
\text { direct } \\
\text { ion } \\
\beta_{2}\left(^{\circ}\right. \\
)\end{array}$ & $\begin{array}{c}\begin{array}{c}\text { Flow } \\
\text { rate }\end{array} \\
V_{f} \\
(\mathrm{~m} / \mathrm{s} \\
)\end{array}$ & $\begin{array}{c}\text { Flow } \\
\text { directi } \\
\text { on } \\
\beta_{3}\left(^{\circ}\right. \\
\left.{ }^{\circ}\right)\end{array}$ \\
\hline B1 & 0.6 & 4 & 90 & 15 & 90 & 0.6 & 180 \\
\hline B2 & 0.6 & 4 & 90 & 15 & 90 & 0.6 & 90 \\
\hline B3 & 0.6 & 4 & 90 & 15 & 135 & 0.6 & 180 \\
\hline B4 & 0.6 & 4 & 135 & 15 & 135 & 0.6 & 180 \\
\hline B5 & 0.6 & 4 & 135 & 15 & 135 & 0.6 & 135 \\
\hline B6 & 0.6 & 6 & 90 & 15 & 90 & 0.6 & 180 \\
\hline B7 & 0.6 & 6 & 90 & 15 & 90 & 0.6 & 90 \\
\hline B8 & 0.6 & 6 & 90 & 15 & 135 & 0.6 & 180 \\
\hline B9 & 0.6 & 6 & 135 & 15 & 135 & 0.6 & 180 \\
\hline B10 & 0.6 & 6 & 135 & 15 & 135 & 0.6 & 135 \\
\hline B11 & 0.8 & 6 & 90 & 15 & 90 & 0.6 & 180 \\
\hline B12 & 0.8 & 6 & 90 & 15 & 90 & 0.6 & 90 \\
\hline B13 & 0.8 & 6 & 90 & 15 & 135 & 0.6 & 180 \\
\hline B14 & 0.8 & 6 & 135 & 15 & 135 & 0.6 & 180 \\
\hline B15 & 0.8 & 6 & 135 & 15 & 135 & 0.6 & 135 \\
\hline
\end{tabular}

IV. Calculation AND ANAlysis OF Hydrodynamic PERFORMANCE OF SHIPS IN NEAR-ISLAND REEF FLOATING PLATFORM

\section{A. Hydrodynamic calculation of the ship near the island reef floating platform}

In the calculation process, the island reef is regarded as a fixed submerged body, which simulates the coupling between the island reef, the floating platform and the supporting ship. Based on the potential flow software AQWA, the floating platform is subjected to frequency domain calculation under the condition of the ship under the working condition, and the hydrodynamic parameter library in the frequency domain is obtained. The hydrodynamic parameter library includes: six degrees of freedom RAO for semi-submersible platforms, first-order wave forces and additional mass 。

\section{B. Frequency Domain Change and Analysis of RAO}

It is calculated that the platform (without mooring) has seven wave angles $\left(90^{\circ}, 105^{\circ}, 120^{\circ}, 135^{\circ}, 150^{\circ}\right)$ when there is a ship in the frequency range of $0.1 \mathrm{rad} / \mathrm{s}$ to $2.0 \mathrm{rad} / \mathrm{s}$. The amplitude response operator RAO, first-order wave force and second-order wave force at $165^{\circ}$ and $180^{\circ}$, the wave angle distribution is shown in Figure 3.

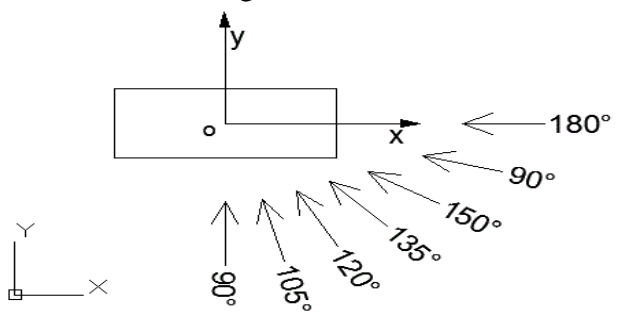

Fig.3 Wave directions

Figure 4 shows the six-degree-of-freedom amplitude response operator RAO of the near-island reef floating platform with or without the ship's support when different wave angles are used. Surge, Sway, Heave, Roll, Pitch, and Yaw respectively represent the platform. The amplitude response operator RAO value in the direction of sway, sway, heave, roll, pitch and roll. 
Figure 4 (a) and Figure 4 (b): When the platform has a ship, the RAV amplitude response operator RAO changes little and has little effect. Figure 4(c) and Figure 4(d): When the platform has a ship, the traverse amplitude response operator RAO decreases significantly around the wave angle of $90^{\circ}$, and is basically near the wave angle of $180^{\circ}$. no change. Figure 4(e) and Figure 4(f): When the platform has a ship, the heave amplitude response operator RAO has almost no change in the low frequency range, and the frequency increases with the increase of the circular frequency in the high frequency range. It gets smaller quickly. Figure 4 (g) and Figure $4(\mathrm{~h})$ : When the platform has a ship, the RAO has a significantly reduced maximum value near the wave angle of $90^{\circ}$, and the RAO is swayed in the high frequency range. The increase in the circular frequency is rapidly becoming smaller. Figure 4(i) and Figure 4(j): When the platform has a ship, the pitching RAO has almost no change in the low frequency range, and the vertical rotation of the RAO decreases rapidly with the increase of the circular frequency in the high frequency range. . Figure 4(k) and Figure 4(1): When the platform has a ship, the RAO shakes very little in the low frequency range, and in the high frequency range, the RAO is rapidly reduced as the circular frequency increases. Small.

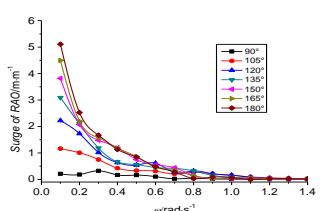

(a) surge RAO (No Ship Docking)

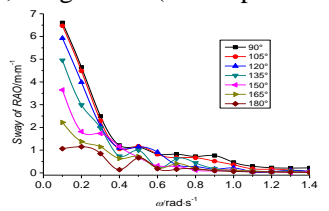

(c) sway RAO (No Ship Docking)

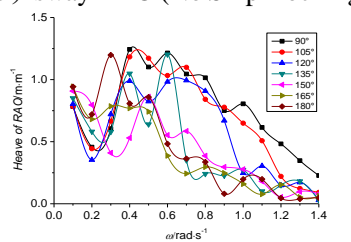

(e) heave RAO (No Ship Docking)

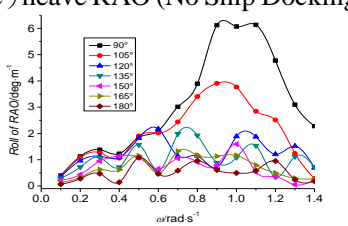

(g) roll RAO (No Ship Docking)

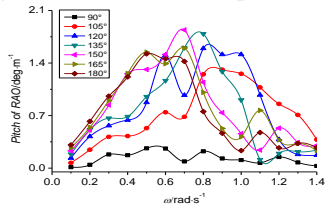

(i) pitch RAO (No Ship Docking)

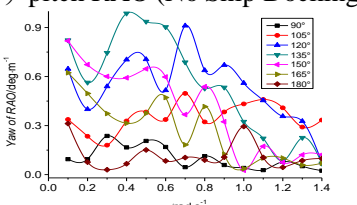

(k) yaw RAO (No Ship Docking)

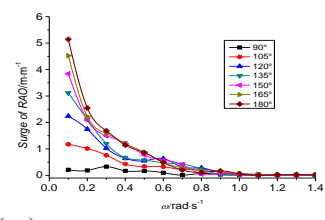

(b) surge RAO (Ship Docking)

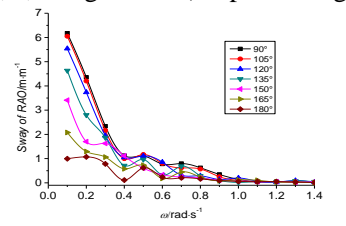

(d) sway RAO (Ship Docking)

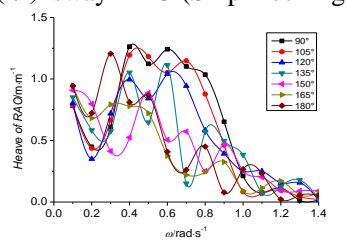

(f) heave RAO (Ship Docking)

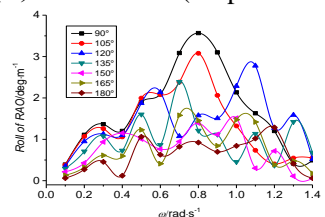

(h) roll RAO (Ship Docking)

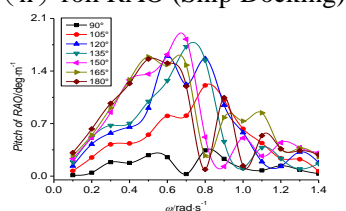

(j) pitch RAO (Ship Docking)

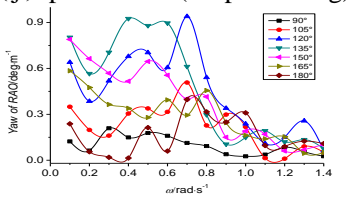

(1) yaw RAO (Ship Docking)
Fig.4 RAO of floating platform in different wave angle

\section{Frequency domain variation and analysis of first-order wave forces}

Figure 5 shows the transfer curve function of the first-order wave force of the six-degree-of-freedom near the island reef floating platform with different wave angles, where fwx, fwy, fwz, Mwx, Mwy, Mwz respectively represent The first-order wave force transfer function values of the platform in the direction of sway, sway, heave, roll, pitch and roll.

It can be seen from Fig. 5(a) and Fig. 5(b) that when the platform has a ship to help, the vertical wave force of the platform changes little. It can be seen from Fig. 5(c) and Fig. 5(d) that when the platform has a ship supporting the gang, the swaying first-order wave force of the platform is significantly reduced in the high frequency range at a wave angle of $90^{\circ}$. It can be seen from Fig. 5(e) and Fig. 5(f) that when the platform has the ship supporting the gang, the first-order wave force of the platform is not changed in the low frequency range, and the platform is swaying first-order wave in the high frequency range. The force decreases rapidly as the circular frequency increases. It can be seen from Fig. 5(g) and Fig. 5(h) that when the platform has the ship supporting the gang, in the high frequency range, the platform swaying first-order wave force rapidly increases with the circular frequency at $90^{\circ}$ wave incidence. Reduced. It can be seen from Fig. 5(i) and Fig. 5(j) that when the platform has the ship supporting the gang, in the low frequency range, the platform first wave power is almost unchanged, and in the high frequency range, the platform swayes the first wave. The force decreases rapidly as the circular frequency increases. It can be seen from Fig. 5(k) and Fig. 5(1) that when the platform has the ship supporting the gang, the first wave force of the platform yaw is significantly reduced in the high frequency range.

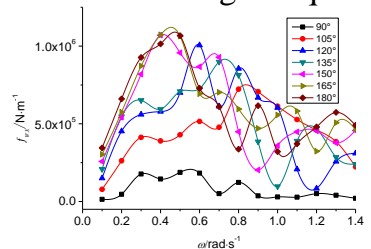

(a) surge of $f_{\mathrm{wx}}$ (No Ship Docking)

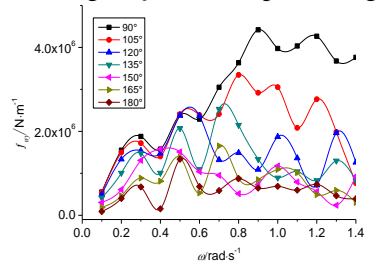

(c) sway of $f_{\mathrm{wx}}$ (No Ship Docking)

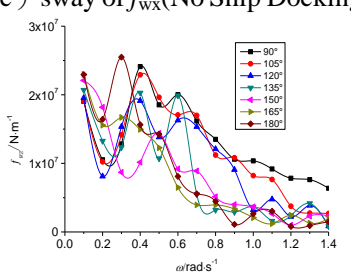

(e) heave of $f_{\mathrm{wx}}$ (No Ship Docking)

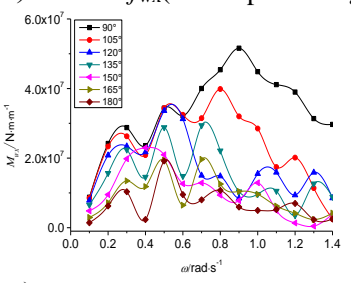

(g) roll of $f_{\text {wx }}$ (No Ship Docking)

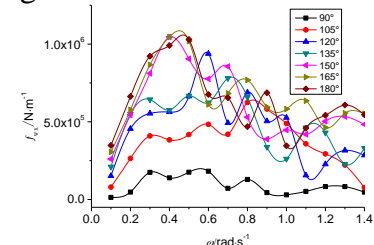

(b) surge of $f_{\mathrm{wx}}$ (Ship Docking)

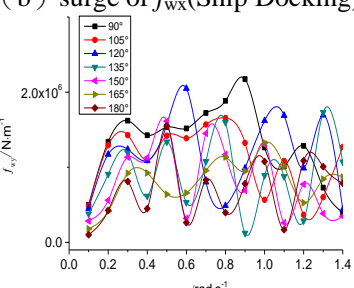

(d) sway of $f_{\mathrm{wx}}$ (Ship Docking)

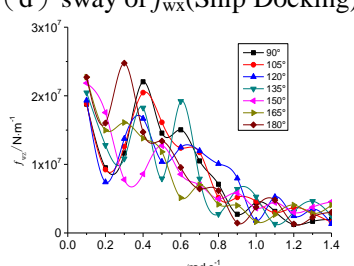

(f) heave of $f_{\mathrm{wx}}$ (Ship Docking)

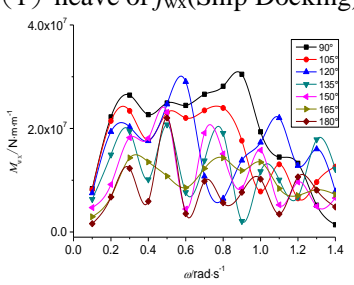

(h) roll of $f_{\mathrm{wx}}$ (Ship Docking) 


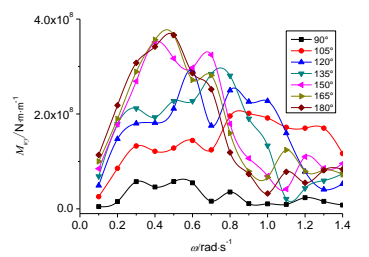

(i) pitch of $f_{\mathrm{wx}}$ (No Ship Docking)

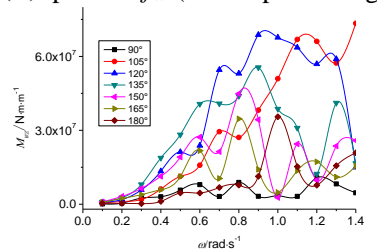

(k) yaw of $f_{\mathrm{wx}}$ (No Ship Docking)

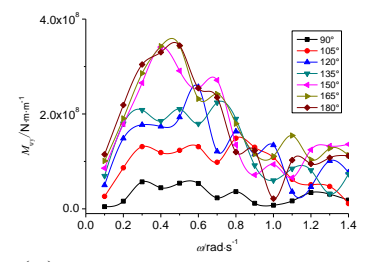

(j) pitch of $f_{\mathrm{wx}}$ (Ship Docking)

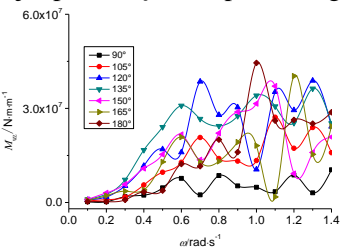

(1) yaw of $f_{\mathrm{wx}}$ (Ship Docking)
D.Fig.5 First order wave excitation force of Frequency domain variation and analysis of additional mass

Figure 6 shows the frequency-domain variation curve of the six-degree-of-freedom additional mass of the near-island reef floating platform with or without the ship's support. The $\mu 11$, $\mu 22, \mu 33, \mu 44, \mu 55, \quad$ and $\mu 66$ are respectively platform-divided. Swinging, swaying, rolling, swaying, and the additional mass value of the swaying direction, as can be seen from the figure:

When the platform has a ship to help, the additional mass of the platform changes little in the direction of the vertical direction, and the overall increase is slightly increased. When the platform has the ship, the additional mass of the platform is heaving, rolling and pitching. The direction is obviously increased in the high frequency range, but the movement trend is consistent; when the platform has the ship supporting, the additional mass of the platform increases significantly in both the sway and the sway, and in the high frequency range The trend of movement has also changed.

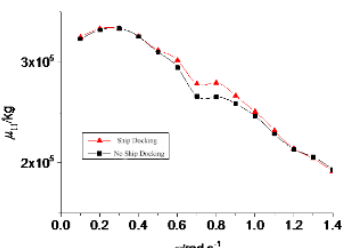

(a) $\mu_{11}^{\text {arads' }}$

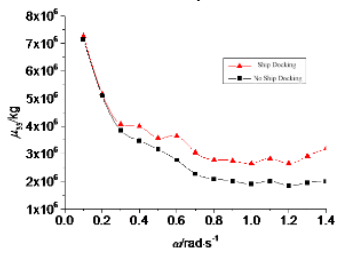

(c) $\mu_{33}$

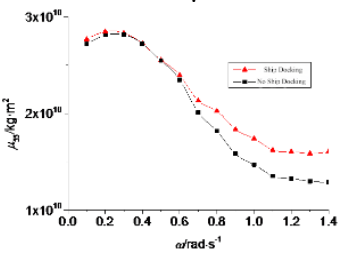

(e) $\mu_{55}$

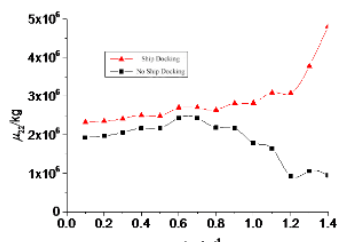

(b) $\mu_{22}^{\text {arads } s^{-1}}$

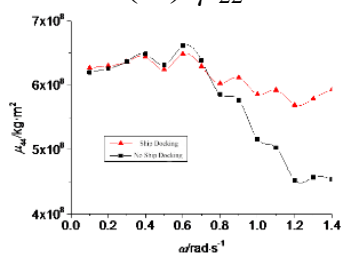

(d) $\mu_{44}$

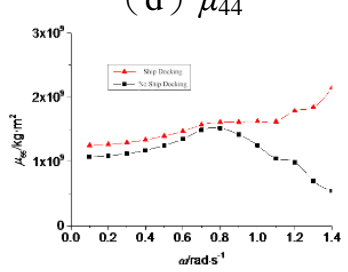

(f) $\mu_{66}$
Fig.6 Added mass of floating platform

\section{CONCLUSION}

By comparing the hydrodynamic parameters of the floating platform without the ship and the ship under the same working conditions, the influence of the ship's support on the platform hydrodynamics is analyzed. Among them, the ship mainly has a greater influence on the sway, heave and roll of the platform, and has less influence on the other three degrees of freedom. At the same time, the RAK reduction of the platform amplitude response operator is more obvious in the high frequency range.

1) The ship has little effect on the RAO in the direction of the platform, but it has a greater impact on the RAO in the other five degrees of freedom of the platform, especially in the high frequency region.

2) In the low frequency range, the ship has little influence on the first-order wave force of the platform; in the high frequency range, the first-order wave force of the platform decreases rapidly as the circular frequency increases.

3) The three-degree-of-freedom of the ship's swaying, heaving and rolling is less affected by the weight of the ship, and the trend of change is the same.

\section{REFERENCES}

[1]Chen Bo, Yu Zhiyong, Li Yujian, et al. Optimization design and performance analysis of high performance tension leg platform $[\mathrm{J}]$. China Mechanical Engineering, 2017, 28(10): 1190-119

[2]Wu Linjian, Wang Yuanzhan, Xiao Zhong, et al. Hydrodynamic response of mobile offshore base connecting members under severe sea conditions[J].Petroleum Exploration and Development, 2016, 43(6):997-100

[3] YAN Enrong, PANG Jianhua, WU Dongwei. Research on Ultimate Strength Reliability of Semi-submersible Platform[J]. Journal of Ship Mechanics, 2011,15(4):371-376.

[4] Chen Bo, Yu Zhiyong, Lu Yong et al. A new anti-pensive semi-submersible drilling platform $[\mathrm{J}]$. Petroleum Exploration and Development, 2017, 44(3): 456-462.

[5] Zhang Wei. Hydrodynamic performance analysis of deep sea semi-submersible drilling platform [D]. Shanghai: Shanghai Jiaotong University, 2006.

[6] Xiao Yuwei,Sun Shumin. Research on the Type of Light Tension Leg Platform Based on AQWA[J]. Science Technology and Engineering, 2012,12(33): 8987-8993

[7] Mansour A M , Huang E W. H -shaped pontoon deepwater floating production semisubmersible $[\mathrm{C}] / /$ Proceedings of the 26th International Conference on Offshore Mechanics and Arctic Engineering. California, USA. OMAE2007-29385.

[8] Clauss G F , Schmittner C E , Stutz K. Freak wave impact on semisubmersibles time-domain analysis of motions and forces[C]// Proceedings of the 13th International Offshore and Polar Engineering Conference, 2003, JSC-371.

[9] Lowa Y M , Langleyb R S. Time and frequency domain coupled analysis of deepwater floating production systems [J].Ap-plied Ocean Research, 2006, 28: 371-385.

Zhidong Wang, Professor, doctoral tutor, Mainly Engaged in Research Work on Fluid Dynamic Performance of Marine and Offshore Engineering, China.

Yaqiu Liu, Postgraduate of Naval Architecture and Ocean Engineering department of Jiangsu University of Science and Technology, China. $+8618851406292$ 